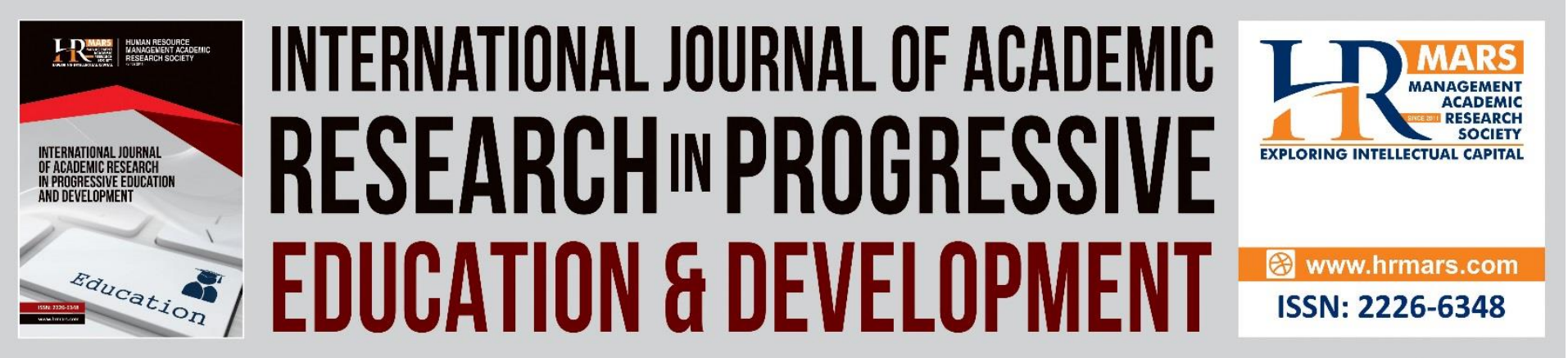

\title{
Conducting Examination in Nigerian Universities: The Quandary of Missing Scripts and Scores
}

Emaikwu, Sunday Oche

To Link this Article: http://dx.doi.org/10.6007/IJARPED/v1-i4/12013

DOI: 10.6007/IJARPED/v1-i4/12013

Received: 16 September 2012, Revised: 20 October 2012, Accepted: 08 November 2012

Published Online: 26 November 2012

In-Text Citation: (Emaikwu, 2012)

To Cite this Article: Emaikwu, S. O. (2012). Conducting Examination in Nigerian Universities: The Quandary of Missing Scripts and Scores. International Journal of Academic Research in Progressive Education and Development, 1(4), 218-233.

Copyright: @ 2012 The Author(s)

Published by Human Resource Management Academic Research Society (www.hrmars.com)

This article is published under the Creative Commons Attribution (CC BY 4.0) license. Anyone may reproduce, distribute, translate and create derivative works of this article (for both commercial and non-commercial purposes), subject to full attribution to the original publication and authors. The full terms of this license may be seen at: http://creativecommons.org/licences/by/4.0/legalcode

\section{Vol. 1(4) 2012, Pg. 218 - 233}

Full Terms \& Conditions of access and use can be found at http://hrmars.com/index.php/pages/detail/publication-ethics 


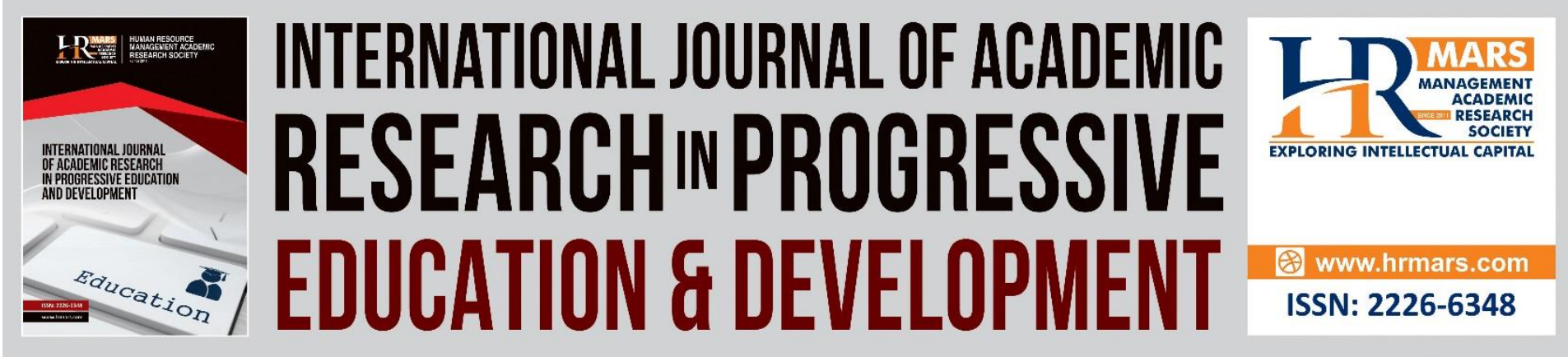

\title{
Conducting Examination in Nigerian Universities: The Quandary of Missing Scripts and Scores
}

\author{
Emaikwu, Sunday Oche PhD \\ Senior Lecturer, Department of Educational Foundations \& General Studies, Federal \\ University of Agriculture, P.M.B. 2373 Makurdi, Benue State, Nigeria \\ Email: emaikwuoche@yahoo.com
}

\begin{abstract}
The purpose of this research work was to assess the causes, consequences and remedies to the incidence of missing scripts and scores in the course of conducting examination in Nigerian universities. The design of this study was survey research design. The sample for the study consisted of 360 students and 140 lecturers randomly selected from three universities in North Central Nigeria using simple random sampling technique. The instrument for data collection was structured questionnaire developed by the researcher and anchored on a continuum of strongly agree to strongly disagree. To carry out the study three research questions were answered using mean and standard deviation while three hypotheses were tested using t-test statistic. The result indicated that the incidence of missing scripts and scores in university could arise when the secretary who types results mistakenly omit some students' vital details, when students do not follow instructions to indicate their individual information correctly and also due to careless attitude of lecturers during marking and scoring of scripts among other factors. The result indicated that one of the consequences of missing scripts and scores is that many brilliant students have been denied good grades and better class of degrees on graduation with many other deleterious effects on students. The result revealed that there was no significant difference in the opinions of students and lecturers on the causes, consequences and remedies to the incidence of missing scripts and scores in universities. It is recommended that examiners should always ensure that the number of scripts they collect tallies with the number of candidates present in the examination hall and avoidance of marking of scripts in public places. Besides there should be good storage of examination scripts and the university authority should if possible, ensure that there is back up for scripts through scanning.
\end{abstract}

Keywords: Nigerian Universities, Conducting Examination, Missing Scripts and Scores, Causes, Consequences and Solutions to Missing Scripts.

\section{Introduction}

Educational institutions are expected to conduct achievement tests regularly to be able to establish the desired characteristics of their examinees. Testing has become one of the most important parameters by which a society adjudges the product of educational system. The essence of testing is to reveal the latent ability of examinee. The term 'ability' connotes the 
characteristics of the examinees that the test is intended to measure. It includes factual knowledge and specific skills as well as more general skills. Emaikwu (2006) affirms that for an examinee's ability to be estimated, the examinee has to respond to a sample of questions. A test score based on this sample of questions or problems could be an approximate indicator of examinee's true ability. Examination as a part of evaluation is aimed at determining a learner's level of skill acquisition or intellectual competence and understanding after a given training. Evaluation usually enables the teacher to be effectively ready for further teaching as this form of evaluation is often regarded as a feedback. But when examination is not properly conducted and the results accurately released, the expected feedback may not result. Consequently the result of such evaluation leads to wrong decision and judgment which affect the teacher, the learner, the entire education industry as well as the society (Emaikwu, 2012). A reality that can not be ignored is that no matter how lofty, how enviable, how laudable, how gigantic the education goals are, how relevant the school curriculum is organized, if no provision is made for accurate evaluation and reportage of learning progress, all these efforts will amount to a wasteful venture (Duze, 2011). Examination could be conducted for the purpose of selection, classification, placement, promotion and certification. For examination to be valid and reliable it has to be administered under conducive and uniform conditions where examinees are made to adhere to stipulated rules and regulations. The primary functions of lecturers in universities include carrying out researches, teaching and examination of students to certify their levels of intellectual competency.

In Nigeria the educational system is crisis-ridden and it is common these days to see lecturers in institutions of learning develop strange attitude and cold feet to work (Oguntimehin, 2006). Most often, classes are skipped and when they are not skipped, they are abrupt; formative and summative evaluations are often handled carelessly; missing scripts cum missing scores abound; lecturers' role as models are no longer the usual parlance. Our citadels of learning have in the recent past and even now been awash with vile practices orchestrated on one hand by students who do not take their studies seriously and on the other, by lecturers who compromise their integrity for ephemeral enjoyment and financial gratification. In the recent time, the issues of sex for marks, missing answer scripts and giving of bribes to enhance a high mark on our campuses have continued to perpetuate as nothing is done tangibly to abate them. A good number of academic staff in universities is directly or indirectly involved in this malady of sex for marks, bribes, missing answer scripts and scores. Some of these lecturers overtly often make the marks scored by their students known to them before they are pasted for all to see so as to create advance awareness and advertisements for those who did not do well to beg for marks either in cash or kind. It is important to note that the purchase of a few lecturer's handouts or textbooks goes a long way to determine who will pass the lecturer's course not minding that there are other similar textbooks in the library that could be read by their students. In the event of not purchasing the lecturer's specified handout or textbooks, one considers oneself as having already failed the lecturer's course or at best has an incomplete result occasioned by missing scripts and scores.

One of the major issues in the examination process in the university that has often pricked and agitated the minds of many persons in the society is therefore the incidence of missing scripts and scores in many departments and faculties in our universities. Stories abound how students after writing their examinations, having signed in and out before and after the commencement of the examinations later found out they are not often given any grade on 
the courses they sat for (Obasi, 2009; Nwaorgu, 2012). It is therefore palpable that many students read with vigour and rigour it deserves before and during examination in many universities in Nigeria but after writing the examination, it turns out to be that they have no scores and grades recorded against their names and registration numbers as a result of missing scripts. This ugly incidence often causes affected students a lot of psychological trauma, helplessness, hopelessness and with other attendant spiral effects on their preparation for subsequent examinations. Many brilliant students have had their academic dreams shattered because they have been denied good grades and better class of degrees as a result of the fact that they have been badly affected by the incidence of missing scripts and scores. This incidence is ubiquitous in many universities in Nigeria and the trend has been on the increase in the recent times (Orji, 2012; Okara, 2012).

Several reasons could be adduced for the causes of incidence of missing scripts and scores in the university system. The incidence of missing scripts could arise when there is a sheer idiosyncrasy on the part of a male lecturer to victimize an 'uncompromising female' student to submit to the whims and caprices of a randy male lecturer. Okocha (2011) reported that in Nigeria, no matter how brilliant a female student is, once a lecturer approaches her for sex and she refuses, her problems start and one of such problem is missing scripts cum missing results. She confessed that she actually became a victim when she refused the advances of a randy lecturer in her department; she was made to spend two extra sessions on account of her script not seen and other flimsy excuses.

The fact about this malady is that most of the time, the secretary who compiles the results could mistakenly omit some results, scores, grades and names of some students if there is any laxity on the part of such personnel involved in the processing of examination results. The examiners sometimes may misplace some scripts during and after examination into unused answer booklet parcels unknowingly. Also the course coordinator and lecturers who mark the scripts can also lose some, especially during recording. It is possible that typist who types the result sheets could also leave out some students' vital details. In some occasions, many students often refuse to submit their answer scripts when it is obviously observed by them that they have not written well enough of what is required of them to pass the course. This often happens when the teaching and examination are conducted with large number of students involved especially in general studies courses. Also missing scripts and scores often occur in universities where students offer similar multiple course combinations such as Mathematics/Statistics/Computer Science/Education, Mathematics/Statistics/Computer Science, etc, and under this situation, errors of commission and transposition could occur. Carelessness on the part of lecturers could result in incidence of missing scripts especially when students' scripts are farmed out' to unauthorized people to assist them to mark and record scores. Sometime scripts could be misplaced when they are being marked in non conducive environments like drinking joints and beer parlours.

Some students sometimes contribute to their woes through late submission of scripts or papers, leaving them vulnerable to omission. Some students often fail to write their names in the necessary attendance lists or fail to sign in and out as required; hence when this occurs, they will not see their results because this is a prerequisite for the release of such results or a proof that the student actually took the examinations. Occasionally some students do not follow the examination rules to indicate their subject combinations accurately and when this 
happens, it is only careful and meticulous lecturers that could patiently sort these scores into appropriate course options otherwise cases of missing scripts and scores could arise. In the case of examinations with multiple choice questions, poor shading of the computer sheets is another factor that may cause students to sit for the same examination twice or thrice if the issue of missing score arises (Chimere, 2012). However, the ugly face of this misfortune is that, no matter whose fault it is, the affected students are compelled by the university authority to bear the brunt of the situation. When students have missing scripts, the courses involved are recorded as failed courses, which the students are expected to carry over and re-sit, even though the students may have performed excellently well in the examinations. According to Orji (2012), this predicament consequently increases the students' unit load and also reduces their cumulative grade point average (CGPA). In some very bad situations, scores of students or even the result of a class may not be released or graded. It is obvious that, in such cases, the fault does not lie with the students but the staff and yet, no explanation is always given and little or no effort is made to rectify these problems and most often the students are made to carry the albatross. Among all the failures of the academic system in Nigeria, this is one of those that hit the students hardest. In many departments in the university, it has become a norm for a class to get its results with one or more missing results affecting certain group of students.

The clarion call to university authorities, lecturers and examiners is to tackle this problem from its roots and reduce it to the barest minimum and in cases of its reoccurrence, the students should be spared of bearing the consequences or punishment as this is very unfair on them. Measures should be taken to see that the students are rightly compensated by retaking the courses and then substituting the results for the missing ones to avoid any harm to the students' CGPA, and general academic performance since this may have some deleterious effect on students' achievement in the university (Orji, 2012). To combat the incidence of missing scripts and scores, the Legislative Council Panel on Education (2004) suggested that university authority should ensure that there is a backup of scripts through scanning and that there should be timely delivery of scripts to markers thereby enabling a prompt start to the marking process. In the same vein, Mettle (2010) opined that security of scripts could be ensured by the avoidance of marking of scripts in public places as well as enhancing strict script movement between markers in double marking. He also submits that efforts should be intensified in marking and capturing of marks in one single process to save time and eliminate errors in mark entry as well as adequate storage of examination scripts and the possibility of on-demand access by candidates to their scripts. The question that may arise is: how feasible are these suggestions amenable to the problem of the incidence of missing scripts in Nigerian universities? Sequel to this background this article is set to examine the actual causes, consequences and remedies to the incidence of missing scripts and score in the university system using the opinions of students and lecturers who are the major stakeholders in this alarming scenario that currently characterize the examination process in Nigerian universities.

\section{Research Question}

To carry out the study, the following research questions were answered:

1. What are the opinions of lecturers and students on the causes of missing scripts and scores in the universities? 
2. What are the opinions of lecturers and students on the consequences of missing scripts and scores in universities?

3. What are the opinions of lecturers and students on the solutions to the problems of missing scripts and scores in universities?

\section{Research Hypotheses}

The following hypotheses were formulated to guide the study and were tested at $5 \%$ level of significance

1. There is no significant difference in the mean perception between lecturers and students on the causes of missing scripts and scores in universities.

2. There is no significant difference in the mean perception between lecturers and students on the consequences of missing scripts and scores in the universities.

3. There is no significant difference in the mean perception between lecturers and students on the solutions to the incidence of missing scripts and scores in the universities.

\section{Research Methodology}

The design of this research is a survey research. The study was carried out in four universities in North Central Nigeria. The population of this study was made up of all the 2011/2012 final year students and all their lecturers in the Faculty of Education in three universities. A total of 3860 respondents formed the students' and lecturers' population for the study. The researcher obtained the information about the population of this study from students' affair units in the four universities. The participants were considered for the study on the ground that they have studied for at least three years and have gotten enough information and experience about the incidence of missing scripts and missing scores in universities. The sample for this study is made up of 500 respondents randomly selected from the population of students and lecturers. The sample was made up of 140 lecturers and 360 students. The sampling technique used in this study was simple random sampling. A structured questionnaire was developed and used for data collection using a four-point rating scale which was anchored on a continuum of strongly agree to strongly disagree with items dealing with the causes, consequences and solutions to incidence of missing scripts and scores in the university. Two specialists in the area of measurement and evaluation as well as a psychologist validated the items of the instrument. The specialists were asked to assess the brevity of the items. The comments given by the specialists were strictly adhered to and appropriate corrections effected. The reliability coefficient of the instrument for this study was 0.89 using Cronbach alpha coefficient. The data collected from the respondents were analyzed according to research questions and the research hypotheses. Descriptive statistics of mean, standard deviation were used to answer the research questions while t- test statistic was used to test the hypotheses at $5 \%$ level of significance.

\section{Results of the Findings}

Research Question 1: What are the opinions of lecturers and students on the causes of missing scripts and scores in the university? Table 1 shows the mean and standard deviation of students' and lecturers' perception about the causes of missing scripts and scores in universities. 
INTERNATIONAL JOURNAL OF ACADEMIC RESEARCH IN PROGRESSIVE EDUCATION AND

DEVELOPMENT

Vol. 1, No. 4, 2012, E-ISSN: 2226-6348 @ 2012 HRMARS

Table 1: Mean and Standard Deviation of Students' and Lecturers' Perception on the Causes of Missing Scripts and Scores in Universities

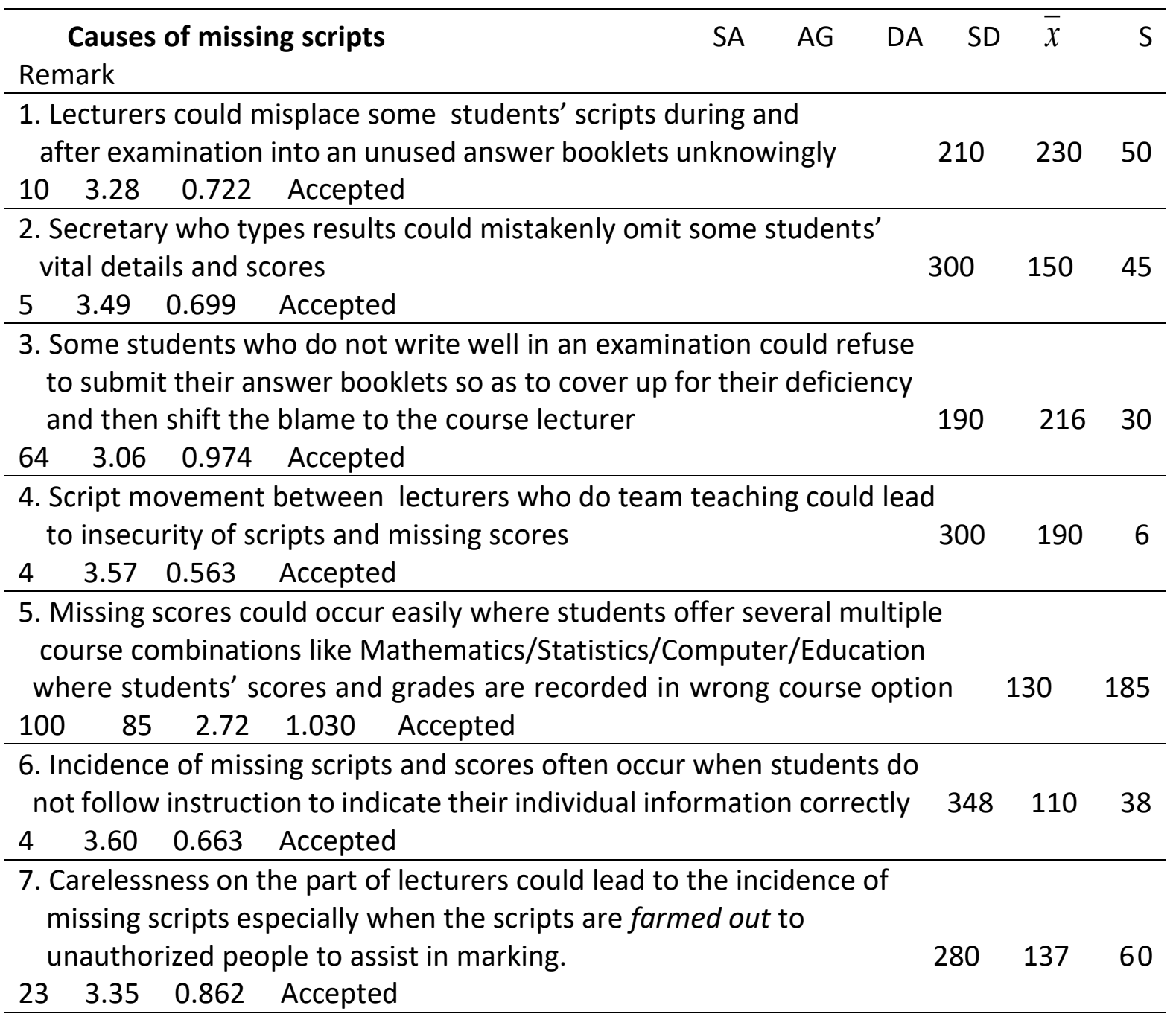

8. Scripts could be misplaced if they are marked in non conducive environments like drinking joints and beer parlours

$183 \quad 199 \quad 28$

$90 \quad 2.95 \quad 1.067$ Accepted

9. In multiple choice questions, poor shading of computer sheet may result

in a student not having a score

235210

$\begin{array}{llll}17 & 3.33 & 0.759 & \text { Accepted }\end{array}$

10 . Scripts could be missed if students refused to sign in and out in an attendance sheet as required

$211 \quad 169 \quad 101$

$\begin{array}{llll}19 & 3.14 & 0.869 & \text { Accepted }\end{array}$

11. Missing script could occur if a female student refuses sexual advances of a male lecturer as means of victimizing her

$160200 \quad 100$ $\begin{array}{llll}40 & 2.96 & 0.916 & \text { Accepted }\end{array}$

From Table 1, any item with a mean response greater than 2.50 is considered as one of the causes of missing scripts and missing scores in universities. For the fact that all the listed items in the table above have mean greater than the benchmark of 2.50, all the items in Table 1 are therefore seen as the causes of missing scripts and missing scores in universities. 
DEVELOPMENT

Vol. 1, No. 4, 2012, E-ISSN: $2226-6348$ C 2012 HRMARS

\section{Research Hypothesis 1}

There is no significant difference in the mean perception between lecturers and students on the causes of missing scripts and scores in universities. To test the hypothesis, an independent t-test is used and the result is presented in Table 2.

Table 2: Mean and Standard Deviation of Students' and Lecturers' Perception on the Causes of Missing Scripts and Scores in Universities as well as their Corresponding two-tailed t-test of Difference between the two Means being Statistically Compared

\begin{tabular}{cccccccc}
\hline Groups & Mean & SD & $\mathbf{N}$ & df & $\alpha$ & t-cal & t- critical \\
Students & 3.29 & 0.775 & 360 & & & & \\
Lecturers & 3.15 & 0.895 & 140 & 498 & 0.05 & 1.63 & 1.96 \\
\hline
\end{tabular}

Table 2 shows that the mean perception of students on the causes of missing scripts and scores in universities was 3.29 and with a standard deviation of 0.775 , while the mean perception of lecturers on the causes of missing scripts and scores in universities was 3.15 and with a standard deviation of 0.895 respectively. The result of the hypothesis showed that the t-calculated value of 1.63 is less than the t-tabulated value of 1.96; hence the test statistic is not significant. The null hypothesis is therefore accepted. This implies that there is no significant difference in the mean perception between lecturers and students on the causes of missing scripts and scores in the universities. Any physical differences observed in the mean perception between lecturers and students on the causes of missing scripts and scores in the universities are such that might have arisen from sampling errors or any other variations in the research exercise.

There is the need to calculate the effect size for this independent sample t-test statistic which yielded no statistical significant result. Effect size statistics provide an indication of the magnitude of the differences between the two groups being statistically compared. The procedure for calculating eta squared for the independent $t$-test statistic is provided by the formula: et squaret $\frac{\mathrm{t}^{2}}{t^{2}+\left(n_{1}+n_{2}-2\right)}$ From Table 2, the t-calculated is $1.63, \mathrm{n}_{1}=360$ and $n_{2}=140$, the eta squared could be calculated by replacing these values in the formula. Hence the et \$quared $\frac{\mathrm{t}^{2}}{t^{2}+\left(n_{1}+n_{2}-2\right)}=\frac{(1.63}{(1.63)^{2}+(36 \theta-14 \theta-2)}=0.0053068 .005$ The guidelines for interpreting the value of eta squared are: $0.01=$ small effect, $0.06=$ moderate effect, $0.14=$ large effect. In this hypothesis, we can see that the eta value of 0.0053 is a small effect size. Expressed as a percentage, (i.e. multiply the effect size by 100), the effect size is 0.53 per cent. In other words, effect size statistic which provides an indication of the magnitude of the difference between the two groups being statistically compared is only 0.53 per cent.

Research Question 2: What are the opinions of lecturers and students on the consequences of missing scripts and scores in the university? Table 3 shows the mean and standard deviation of students' and lecturers' perception about the consequences of missing scripts and scores in universities. 
DEVELOPMENT

Vol. 1, No. 4, 2012, E-ISSN: $2226-6348$ @ 2012 HRMARS

Table 3: Mean and Standard Deviation of Students' and Lecturers' Perception on the Consequences of Missing Scripts and Scores Universities

\begin{tabular}{|c|c|c|c|c|c|c|c|}
\hline & $\begin{array}{l}\text { equence of missing scripts } \\
\text { ark }\end{array}$ & SA & $A G$ & DA & SD & $\bar{x}$ & $\mathrm{~S}$ \\
\hline \multicolumn{5}{|c|}{$\begin{array}{l}\text { 1.Many brilliant students have been denied good grades and better class } \\
\text { of degrees on graduation because of incidence of missing scripts }\end{array}$} & 241 & 211 & 23 \\
\hline 25 & $3.34 \quad 0.784 \quad$ Accepted & & & & & & \\
\hline
\end{tabular}

2. Incidence of missing scripts often causes students a lot of psychological trauma and has spiral effects on their preparation for subsequent examination $212 \quad 200$ $\begin{array}{lllll}38 & 50 & 3.15 & 0.937 & \text { Accepted }\end{array}$

3. Incidence of missing scripts does not affect students negatively as it does not lead them to state of misery, hopelessness, helplessness and worry 109 $\begin{array}{lllll}191 & 290 & 1.47 & 0.637 & \text { Rejected }\end{array}$

4. The burden of missing scripts and scores are felt more on the part of students who will be made to write the course again as carry over thereby increasing their cumulative credit carried

$\begin{array}{llll}30 & 3.23 & 0.794 & \text { Accepted }\end{array}$

5. The affected students are often shunned and harshly scolded by lecturers and university authority when they complain about their missing scores $\begin{array}{lllll}80 & 33 & 3.09 & 0.893 & \text { Accepted }\end{array}$

6 . For the fact that missing scores are treated as failed courses they lead to increase in students' credit units as well as reduce their cumulative grade point average

$\begin{array}{llll}21 & 3.49 & 0.742 & \text { Accepted }\end{array}$

7. Many students who have missing scores are often regarded as unserious and careless students and hence many lecturers are unconcerned about their plights 203186 $\begin{array}{lllll}60 & 51 & 3.08 & 0.829 & \text { Accepted }\end{array}$

From Table 3, any item with a mean response greater than 2.50 is considered as one of the consequences of missing scripts and scores in universities. Among the seven items listed only item number 3 has a mean score of 1.47 which is less than the benchmark of 2.50. For the fact that all other listed items in the table above have their means greater than the benchmark of 2.50, they are therefore seen as the consequences of missing scripts and scores in universities. The respondents were in affirmative that the incidence of missing scripts affects students negatively as it leads them to a state of misery, hopelessness, helplessness and worry in universities among other consequences.

Research Hypothesis 2: There is no significant difference in the mean perception between lecturers and students on the consequences of missing scripts and scores in the universities.

Table 4: Mean and Standard Deviation of Students' and Lecturers' Perception on the consequences of missing scripts and scores in the university as well as their corresponding two-tailed t-test of difference between the two means being compared 


\begin{tabular}{cccccccc}
\hline Groups & Mean & SD & N & df & $\alpha$ & t-cal & t-critical \\
Students & 3.24 & 0.838 & 360 & & & & \\
Lecturers & 3.22 & 0.821 & 140 & 498 & 0.05 & 0.243 & 1.96 \\
\hline
\end{tabular}

Table 4 shows that the mean perception of students on the consequences of missing scripts and scores in universities was 3.24 and a standard deviation of 0.838 , while the mean perception of lecturers on the consequences of missing scripts and scores in universities was 3.22 and with a standard deviation of 0.821 respectively. The result of the hypothesis showed that the t-calculated value of 0.234 is less than the $t$-tabulated value of 1.96 ; hence the test statistic is not significant. The null hypothesis is therefore accepted. This implies that there is no significant difference in the mean perception between lecturers and students on the consequences of missing scripts and scores in the university. Any physical difference observed in the mean perception between lecturers and students on the consequences of missing scripts and scores in the universities are such that might have arisen from sampling errors or any other variations in the research. There is also the need to calculate the effect size for this independent sample t-test statistic which yielded no statistical significant result. From Table 4, the $t$-calculated is $0.243, n_{1}=360$ and $n_{2}=140$, the eta squared is $\frac{(0.24) 3}{(0.24)+(36 \theta+14 \theta-2)}=0.0001185500011$

In this hypothesis, we can see that the eta squared value of 0.0001186 is a very small effect size. Expressed as a percentage, (i.e. multiply the effect size by 100), the effect size is 0.012 per cent. In other words, effect size statistic which provides an indication of the magnitude of the difference between the two groups being statistically compared is only 0.012 per cent.

Research Question 3: What are the opinions of lecturers and students on the solutions to the problems of missing scripts and scores in the universities? Table 5 shows the mean and standard deviation of students' and lecturers' perception on the solutions to problems of missing scripts and scores in the universities. 
DEVELOPMENT

Vol. 1, No. 4, 2012, E-ISSN: $2226-6348$ (C) 2012 HRMARS

Table 5: Mean and Standard Deviation of Students' and Lecturers' Perception on the Solutions to Problems of Missing Scripts and Scores in the Universities

\begin{tabular}{|c|c|c|c|c|c|}
\hline $\begin{array}{l}\text { Strategies for combating missing scripts } \\
\text { Remark }\end{array}$ & $A G$ & DA & SD & $\bar{x}$ & $S$ \\
\hline $\begin{array}{l}\text { 1. There should be back up for scripts through scanning, } \\
\text { to eliminate the problem caused by missing scripts } \\
0.898 \text { Accepted }\end{array}$ & 216 & 200 & 44 & 40 & 3.18 \\
\hline $\begin{array}{l}\text { 2. There should be timely delivery of scripts to markers } \\
\text { to enable a prompt start to the marking process. } \\
0.951 \quad \text { Accepted }\end{array}$ & 181 & 198 & 71 & 50 & 3.02 \\
\hline $\begin{array}{l}\text { 3. There should be security of scripts and avoidance of } \\
\text { marking in public places } \\
0.767 \quad \text { Accepted }\end{array}$ & 230 & 219 & 30 & 21 & 3.32 \\
\hline $\begin{array}{l}\text { 4. Effort should be made to mark and capture marks } \\
\text { in one single process to eliminate errors in mark entry } \\
0.916 \quad \text { Accepted }\end{array}$ & 211 & 190 & 59 & 40 & 3.14 \\
\hline $\begin{array}{l}\text { 5. Ensure water tight movement of script between markers } \\
\text { in double marking so as to improve security of scripts } \\
0.837 \quad \text { Accepted }\end{array}$ & 180 & 216 & 80 & 24 & 3.10 \\
\hline $\begin{array}{l}\text { 6. There should be reduction in the processing time of student } \\
\text { scripts and an earlier release of results } \\
0.987 \quad \text { Accepted }\end{array}$ & 100 & 213 & 100 & 87 & 2.65 \\
\hline $\begin{array}{l}\text { 7.There should be proper storage of examination scripts and t } \\
\text { possibility of on-demand access by candidates to their scripts } \\
0.895 \quad \text { Accepted }\end{array}$ & $\begin{array}{l}\text { the } \\
\text { ts } 215\end{array}$ & 200 & 46 & 39 & 3.18 \\
\hline $\begin{array}{l}\text { 8. Ensure that the number of scripts collected tallies with the } \\
\text { number of candidates present in the examination hall } \\
0.563 \quad \text { Accepted }\end{array}$ & 209 & 261 & 19 & 21 & 3.36 \\
\hline
\end{tabular}

From Table 5, all the listed items have mean rating greater than the benchmark of 2.50 and are therefore regarded as the solutions to the incidence of missing scripts and scores in universities.

Research Hypothesis 3: There is no significant difference in the mean perception between lecturers and students on the solutions to the incidence of missing scripts and scores in the university. The result of this hypothesis is presented in Table 6.

Table 6: Mean and Standard Deviation of Students' and Lecturers' Perception on the Solutions to the Incidence of Missing Scripts and Scores in the Universities as well as their Corresponding two-tailed t-test of Difference between the Two Means being Compared

\begin{tabular}{cccccccc}
\hline Groups & Mean & SD & N & df & $\alpha$ & t-cal & t- critical \\
Students & 3.16 & 0.883 & 360 & & & & \\
Lecturers & 3.06 & 0.815 & 140 & 498 & 0.05 & 1.20 & 1.96 \\
\hline
\end{tabular}

Table 6 shows that the mean perception of students on the solution to the incidence of missing scripts and scores in university was 3.16 and standard deviation of 0.883 , while the 
mean perception of lecturers on the solution to the incidence of missing scripts and scores in universities was 3.06 and with a standard deviation of 0.815 respectively. The result of the hypothesis showed that the t-calculated value of 1.20 is less than the t-tabulated value of 1.96; hence the test statistic is not significant. The null hypothesis is therefore accepted. This implies that there is no significant difference in the mean perception between lecturers and students on the solutions to the incidence of missing scripts and scores in the universities. Any physical difference observed in the mean perception between lecturers and students on the solution to the incidence of missing scripts and scores in the universities are such that might have arisen from sampling errors or any other variations in the research. The effect size for this independent sample t-test statistic which yielded no statistical significant result with the $\mathrm{t}$-calculated $=1.20, \quad \mathrm{n}_{1}=360$ and $\mathrm{n}_{2}=140$ is $\frac{(1.2)}{(1.20)^{2}+(36 \theta+14 \theta-2)}=0.002883220200 .0028$

In this hypothesis, we can see that the eta value of 0.00288 is a very small effect size. Expressed as a percentage, the effect size is 0.288 per cent. In other words, effect size statistics which provides an indication of the magnitude of the difference between the two groups being statistically compared is only 0.288 per cent.

\section{Discussion of Findings}

From Table 1, for the fact that all the listed items in that table have mean rating greater than the benchmark of 2.50, all the items in that table are therefore seen as the causes of missing scripts and scores in the universities. From this study missing scripts and scores could arise during script movement between lecturers who do team teaching, when students do not follow instructions carefully to indicate their individual information correctly and when secretary who types results mistakenly omit some students' vital details and scores. Moreover, carelessness on the part of lecturers could lead to the incidence of missing scripts especially when the scripts are farmed out to unauthorized people to assist in marking and if the scripts are marked in non conducive environments like drinking joints and beer parlour. In multiple choice questions, poor shading of computer sheet may result in a student not having a score. In addition, missing script could occur if a female student refuses sexual advances of a male lecturer as means of victimizing her. These findings support in part the earlier result by Okocha (2011) who reports that in Nigeria, no matter how brilliant a female student is, once a lecturer approaches her for sex and she refuses, her problems start and one of such problem is missing scripts cum missing results. She confessed that she actually became a victim when she refused the advances of a randy lecturer in her department; she was made to spend two extra sessions on account of her script not seen and other flimsy excuses. The result also affirms the submission of Chimere (2012) who maintains that in the case of examinations with multiple choice questions, poor shading of the computer sheets is a major factor that may cause students to sit for the same examination twice or thrice if the affected student has a missing scores.

From Table 2 it can be seen that the mean perception of students on the causes of missing scripts and scores in universities was 3.29 and with a standard deviation of 0.775 , while the mean perception of lecturers on the causes of missing scripts and scores in universities was 3.15 and with a standard deviation of 0.895 respectively. The result of the hypothesis showed 
that the t-calculated value of 1.63 is less than the t-tabulated value of 1.96; hence the test statistic was not significant. The null hypothesis was therefore accepted. This implies that there was no significant difference in the mean perception between lecturers and students on the causes of missing scripts and scores in the universities. Any physical differences observed in the mean perception between lecturers and students on the causes of missing scripts and scores in the universities were such that might have arisen from sampling errors or any other variations in the research exercise. The effect size statistics which provides an indication of the magnitude of the differences between the two groups being statistically compared was only 0.53 per cent indicating that the lecturers and students were in affirmative on the factors that are responsible for the incidence of missing scripts and scores in universities. This result invariably confirms the assertion by Orji (2012) who maintained that missing scripts have become the plight of students in tertiary institutions and that the stakeholders are aware of its causes and existence.

From Table 3, among the seven items listed as the consequences of missing scripts and scores, only item number 3 has a mean score of 1.47 which was less than the bench mark of 2.50. For the fact that all other listed items in that table have their means greater than the benchmark of 2.50, all of them are therefore seen as the consequences of missing scripts and scores in universities. The respondent were in affirmative that the incidence of missing scripts affects students negatively as it leads them to a state of misery, hopelessness, helplessness and worry in universities. The incidence of missing scripts and scores often causes students a lot of psychological trauma and has spiral effects on their preparation for subsequent examination. Precisely, many brilliant students have been denied good grades and better class of degrees on graduation because of incidence of missing scripts. The burden of missing scripts and scores are felt more on the part of students who will be made to write the course again as carry over, thereby increasing their cumulative credit carried. The affected students are often shunned and harshly scolded by lecturers and university authority when they complain about their missing scores. For the fact that missing scores are treated as failed courses they lead to increase in students' credit units as well as reduce their cumulative grade point average. Many students who have missing scores are often regarded as unserious and careless students and hence many lecturers are unconcerned about their plights. These findings partly support the assertion of Chimere (2012) who affirms that the ugly face of missing scripts is that, no matter whose fault it is, the affected students are compelled by the university authority to bear the brunt of the situation. He reported that when students have missing scripts, the courses involved are recorded as failed courses, which the students are expected to carry over and re-sit, even though the students may have performed excellently well in the examinations.

The result of the hypothesis in Table 4 showed that the t-calculated value of 0.234 is less than the t-tabulated value of 1.96; hence the test statistic is not significant. The null hypothesis was therefore accepted. This implies that there was no significant difference in the mean perception between lecturers and students on the consequences of missing scripts and scores in the universities. Any physical differences observed in the mean perception between lecturers and students on the consequences of missing scripts and scores in the universities were such that might have arisen from sampling errors or any other variations in the research. In that hypothesis, the effect size statistic which provides an indication of the magnitude of the difference between the two groups being statistically compared was only 0.012 per cent. 
From Table 5, all the listed items have mean rating greater than the benchmark of 2.50 and are therefore regarded as the solutions to the incidence of missing scripts in universities. The incidence the incidence of missing scripts and missing scores could be reduced if the examiners ensure that the number of scripts they collect tallies with the number of candidates present in the examination hall and if they avoid of marking of scripts in public places. In addition, the respondents affirmed that there should be back up for scripts through scanning and proper storage of examination scripts with the possibility of on-demand access by candidates to their scripts. Above all the respondents agreed that the incidence of missing scripts and scores will be drastically reduced if there is water tight movement of script between markers in double marking

From Table 6, the mean perception of students on the solution to the incidence of missing scripts and scores in universities was 3.16 and standard deviation of 0.883 while that of lecturers were 3.06 and 0.815 respectively. The result of the hypothesis showed that the tcalculated value of 1.20 is less than the t-tabulated value of 1.96; hence the test statistic is not significant. The null hypothesis was therefore accepted. This implies that there was no significant difference in the mean perception between lecturers and students on the solutions to the incidence of missing scripts and scores in the universities. The physical difference observed in the mean perception between lecturers and students on the solution to the incidence of missing scripts and scores in the universities were such that might have arisen from sampling errors or any other variations in the research. The effect size statistics which provides an indication of the magnitude of the differences between the two groups being statistically compared was only 0.288 per cent. This result agrees with the suggestion of Legislative Council Panel on Education (2004) that to combat the incidence of missing scripts and scores, the university authority should ensure that there is a backup of scripts through scanning and that there should be timely delivery of scripts to markers thereby enabling a prompt start to the marking process. In the same vein, this result affirms the suggestion by Mettle (2010) who opined that security of scripts could be ensured by the avoidance of marking of scripts in public places as well as enhancing strict script movement between markers in double marking thus improving security of scripts. He also submits that efforts should be intensified in marking and capturing of marks in one single process to save time and eliminate errors in mark entry as well as proper storage of examination scripts with the possibility of on-demand access by candidates to their scripts

\section{Conclusion}

Based on the findings of this study, it could be concluded that the calamity of missing scripts is not just the havoc it is wrecking on the affected students but also the gradual psychological worry, state of hopelessness and helplessness that the entire students are subjected to as a result of this new trend of issue in universities.

Moreover, it could also be observed that the incidence of missing scripts and scores in university could arise when the secretary who types results mistakenly omit some students' vital details, when students do not follow instructions to indicate their individual information correctly and also due to careless attitude of lecturers during marking and recording of scripts among other factors. 
The result indicated that one of the consequences of missing scripts and scores is that many brilliant students have been denied good grades and better class of degrees on graduation because of the incidence of missing scripts. It can also be affirmed that the burdens of missing scripts and scores have many deleterious effects on students.

In addition, the result revealed that there was no significant difference in the opinions of students and lecturers on the causes, consequences and remedies to the incidence of missing scripts and scores in universities.

Conclusively, the incidence of missing scripts and scores could be curtailed if appropriate affirmative measures are taken by the stakeholders in the university system. The security of scripts could be guaranteed if lecturers avoid marking of scripts in public places, enhance strict script movement between markers in double marking, ensure that the number of scripts collected tallies with the number of candidates present in the examination hall and create back up for scripts through scanning.

\section{Recommendations}

Based on the findings of this study, the following recommendations are suggested:

1. Security of scripts should be ensured by the avoidance of marking of scripts in public places as well as enhancing strict script movements between markers in double marking.

2. The university authority should ensure that there is back up for sensitive scripts through scanning so as to eliminate the incidence of missing scripts.

3. There should be good storage of examination scripts and the possibility of on-demand access by candidates to their scripts.

4. Examiners should always ensure that the number of scripts they collect tallies with the number of candidates present in the examination hall.

5. A candidate whose script is confirmed as missing should be given an assessed grade by reference to his or her performance in continuous assessment scores in the subject or other paper(s) taken using appropriate missing data treatment method.

6. Effort should be made by lecturers to mark scripts and capture marks in one single process to eliminate errors in mark entry.

7. Any lecturer who has confirmed receipt of a script and subsequently reports its loss without any acceptable reason should be sanctioned.

\section{References}

Chimere, I. O. (2012). The decay in Nigerian educational system: The way forward. Journal of Sociological Perspective, 3 (2), 38-46

Duze, C. O. (2011). Falling standard of education in Nigeria education: traceable to proper skill-acquisition. Educational research 2 (1), 803-808, retrieved on $29^{\text {th }}$ February 2012 from_http://www.interestjournal.org

Emaikwu, S. O. (2006). Fundamentals of test, measurement and evaluation with psychometric theories. Kaduna: Datura Prints Nig. Ltd.

Emaikwu, S. O. (2012).Assessing the impact of examination malpractices on the measurement of ability in Nigeria. International Journal of Social Sciences and Education, 2 (4),

748-757.Retrieved from $h t t p: / / i j s s e . c o m$

Legislative Council Panel on Education. (2004). Review on the handling of missing examination 
scripts by the Hong Kong Examinations and Assessment Authority LC Paper No. $C B(2) 2318 / 03-04(01)$

Mettle, K. J. (2010). Man spends night at station guarding answer scripts. Retrieved on April 7, 2012 from http://tnnacademicmirror.com

Nwaorgu, F. C. (2012). Missing answer script, 'sorting', and sex for marks in our universities: Matters arising. Retrieved on January 31st, 2012 from http;//pointblanknews.com

Obasi, E. (2009). Certificate Syndrome. Owerri: Statesman Publishers Ltd.

Oguntimehin, Y. A. (2006). Managing stress in the teaching profession. International Journal of Applied Psychology and Human Performance, 1(1): 75-89.

Okocha, O. G. (2011), Sex for marks: The virus destroying Nigerian schools. The New, p. 17. Retrieved on March 7, 2011 from http://follow@thenewsnigeria

Okara, V. (2012). When a university site swims in politics. The Nation, p. 9. Retrieved on Friday March 09, 2012 from http://www.sunnewsonline.com.

Orji, C. (2012). The mystery of missing scripts. The Nation, p. 16. Retrieved on $16^{\text {th }}$ January 2012 from http://www.the nationnewspaperonlineng.net 